phenomena, though fever persists; and, conversely, drug fever may itself complicate the picture. The temperature chart repars study, for it may suggest malaria, Hodgkin's disease, typhoid, or relapsing fever. A routine should include examination of a mid-stream specimen of urine, faeces, throat swab, chest radiograph, leucocyte count, stained blood film, and blood culture. Serum for antibody levels is obtained early in the illness as a baseline for comparison with convalescent-phase sera. The cerebrospinal fluid is examined if there is persistent headache or the suspicion of meningism. If a diagnosis cannot be established by this primary investigation, then other possibilities demand consideration-such as a localized collection of pus, a collagen disorder, hepatic cirrhosis, reticulosis, or malignant disease. But despite a systematic approach and exhaustive investigation many pyrexias defy present-day methods of diagnosis, and even follow-up several years later fails to provide a retrospective diagnosis.

P. Effersøe ${ }^{12}$ has conducted such a follow-up of patients who attended the department of contagious diseases at the Blegdamshospital, Copenhagen, during the four calendar years 1960-3 because of continuous fever daily for at least 10 days. During this time 512 periods of continuous fever were documented in 494 patients. The broad diagnostic categories for these bouts of fever comprised infections in $69 \%$, vascular disorders (8\%), neoplasia (6\%), and collagen disorders $(3 \%)$, but no diagnosis could be established in 34 $(7 \%)$ cases. Between the ages of 15 and 65 years the sex incidence was equal, whereas below 15 years there were twice as many boys and over 65 years there were twice as many women as men in all diagnostic categories.

In the spring of 1967 -that is, three to seven years after their period of continuous fever-Effersøe ${ }^{2}$ traced the subsequent health of the 34 patients in whom the fever had remained of unknown origin. The cause of the fever was found to have been established with certainty only in two instances, both within the first year; one patient showed evidence of Hodgkin's disease and the other of the Budd-Chiari syndrome of hepatic-vein thrombosis. In six patients a tentative retrospective follow-up diagnosis of cytomegalovirus infection seemed possible. Follow-up examination underlined the facts that it is only rarely possible to uncover subsequently the cause of continuous fever which has defied initial diagnosis and that the majority of such patients completely recover.

\section{Immigrants and Venereal Disease}

In a report ${ }^{12}$ presented to the executive board of the World Health Organization in 1964 the Director General described movements of population as one of the important factors concerned in the spread of venereal diseases. It is indeed well known that special temptations assail those who are temporarily or permanently separated from their families and homes, whether they are businessmen visiting Continental capitals, commercial travellers, seamen, long-distance lorry drivers, migrant workers, or immigrants acting as forerunners for their wives and families. It was inevitable, therefore, that immigrants to this country, whether temporary or permanent, would help to inflate the numbers of cases of venereal infection.

Over the years the extent of the contribution provided by these newcomers, who seem for the most part to catch these infections here rather than bring them with them, has been studied by the Co-operative Clinical Group of the Medical Society for the Study of the Venereal Diseases and reported in a series of useful publications. The latest of these studies ${ }^{3}$ concern the incidence of early-that is, primary and secondary-syphilis and of gonorrhoea in 1967, and relate the information to the countries of origin of infected patients. Information on 1,341 patients with primary or secondary syphilis was collected from 186 clinics in England, Wales, and Scotland, comprising $93 \%$ of the cases reported from all clinics in England and Wales in that year and $99 \%$ of those reported in Scotland. The male:female ratio was 4.3: 1 in England and Wales and 3.0:1 in Scotland, as compared with $2 \cdot 8: 1$ and $2 \cdot 5: 1$ respectively for gonorrhoea. The report attributes this disparity to the fact that male homosexuals form a higher proportion of those with early syphilis than of those with gonorrhoea, but it seems likely that early syphilis acquired by seamen abroad also contributed to the difference. The longer incubation period of syphilis makes it less likely that such a condition will have been recognized and treated in a seaman before he reaches a home port.

Of 996 men treated in England and Wales, 607 (61\%) were born in the United Kingdom and 389 (39\%) in other countries. The biggest contribution, $10 \%$ of the total, came from those born in Asia, followed by $9 \%$ from the West Indies and $8 \%$ from European countries excluding the Mediterranean area. In Scotland there were only 84 cases in men, and 61 of the patients were born in the United Kingdom. Of 233 infected women in England and Wales, 204 $(88 \%)$ were born in the United Kingdom, 7 in the West Indies, and 6 in Asia. Patients from other areas were very few indeed. The report makes the interesting point that the incidence of infectious syphilis appeared to be exceptionally low among African and West Indian negroes who came from areas where yaws is endemic. Only 28 cases of infectious syphilis in females were reported from Scotland, and all these patients were born in the United Kingdom.

As regards gonorrhoea, information from the same clinics in England and Wales showed a total of 27,979 cases in men and 10,087 in women. The numbers for Scotland were 2,092 in men and 843 in women. Of men with gonorrhoea in England and Wales $56 \%$ were born in the United Kingdom, $17 \%$ in the West Indies, and $7.5 \%$ in Asia. In Scotland $88 \%$ of the men were born in Great Britain. Of the women treated in England and Wales, $82 \%$ were born in the United Kingdom and in Scotland $96 \%$.

It is clear that immigrants here as everywhere continue to make a contribution to the increasingly serious problem of venereal disease. But there are indications that, as the numbers of unaccompanied immigrant men decrease and those already here are joined by their families, the contribution they make to the total is relatively less. It is of particular interest that the proportion of men from abroad treated for infectious syphilis in England and Wales in 1966, as determined in the equivalent study for that year, was $50 \%$, but in 1967 it had fallen to $39 \%$. The figures for gonorrhoea in males were $45.4 \%$ in 1966 and 43.6 in 1967 . The proportional contri-

1 Chronicle of the World Health Organization, 1964, 18, 451.

- Chronicle of the World Health Organization, 1965, 19, 7.

3 British fournal of Venerea! Diseases, 1968, 44, 307.

4 British Fournal of Venereal Diseases, 1968, 44, 299. 
bution of immigrants to the incidence of this disease has fallen progressively since 1962 , when it was $56 \%$. So many additional and variable factors are involved in this problem that it is difficult to draw firm conclusions from these figures. Nevertheless, the Co-operative Clinical Group has for a number of years provided information on this important subject which is not available from other sources. It is to be hoped that this valuable yearly analysis of the facts will continue to be available.

\section{B.M.A at Aberdeen}

At the end of June regular travellers on the sleeper from King's Cross were submerged in a tide of doctors carrying golf-clubs. Aberdeen is famous for its golf-courses, and during the ten days of the 137th Annual Meeting of the B.M.A. several hundred balls disappeared for ever into the impenetrable rough. Sir James Howie, the President, has pointed out that the previous meetings of the Association in Aberdeen were in 1914 and 1939, but that the third time is traditionally lucky.

Aberdeen's new university campus is alongside King's College, whose buildings date from 1500 , and the contrasting styles provided an outstanding setting for the Meeting. The Annual Representative Meeting was held in the Elphinstone Hall of King's College, and, appropriately enough, for the scientific sessions doctors moved up the hill to the Natural Philosophy Building, with its roof garden, fountains, and spacious lighting. But the basis of the undoubted success of the Meeting was the hospitality given to the visitors. On the first evening the City of Aberdeen Division joined with the Aberdeen and Kincardine Counties Division to provide the Welcome Reception at Marischal College, a twentieth century building in white granite which dominates the city. Successive nights saw the Representatives' Dance at the Beach Ballroom, the Civic Reception, and a variety of reunion dinners, so that by the weekend most visitors were glad of a respite in which they could explore the countryside around Balmoral and the Cairngorms.

On Sunday the official religious service was held in the fourteenth century cathedral of St. Machar, where Dr. A. C. Craig preached a memorable sermon on the responsibilities of medical scientists. The President's Reception was another very successful occasion, and the formal events of the Meeting concluded with the Annual Dinner.

The Scientific Meeting had the advantage that all its sessions took place under one roof. Standards were high, but there was a particularly attentive audience for the symposium on experience of therapeutic abortion in Northeast Scotland, at which Professor Ian MacGillivray and his colleagues described their efforts to make a scientific study of the effects of advising abortion or continuation of pregnancy in a large population of women. The Dawson Williams lecture on paediatrics in Vietnam reminded doctors of the enormous problems of medical care in underdeveloped countries.

The Ladies programme, organized by Mrs. Ian Gordon, made full use of the virtues of Aberdeen as a touring centre, and in the Ladies' Club at Crombie Hall Scottish tweeds and woollens were on sale for those wanting mementoes of their visit. The Association is much indebted to those who worked so hard to make the Meeting a success, and special thanks are $\underline{\square}$ due to Dr. N. S. Clark, the Science Secretary, Mr. J. Kyle, $\frac{7}{3}$ the General Secretary, and to Dr. S. G. Davidson, the Chair- $\mathbb{Q}$ man of the Local Organizing Committee.

The first part of the scientific proceedings is reported at $\ddot{\vec{F}}$ p. 162 of this issue, and the account of the A.R.M. is con- $\frac{\mathscr{O}}{0}$ cluded in the Supplement at p. 69.

\section{A Good A.R.M.}

At Aberdeen the Annual Representative Meeting came much nearer than usual to completing its business. For a body of over 400 members facing an agenda of some 420 J items this was a notable achievement, and one for which the credit must largely go to the procedural innovations intro- $\vec{N}$ duced last year and this. The Organization Committee and its chairman, Dr. John Noble, who initiated the reforms, are to be congratulated on the fruit of their labours.

Provision was made at the A.R.M. at Eastbourne in $1968 \subseteq$ for the calling of ad hoc meetings of representatives to seek agreement on related motions tabled by their constituencies. $\mathscr{\odot}$ This procedure saved the Meeting at Aberdeen this year from a muddle during a debate on certification. The representatives concerned met and brought back an agreed wording for debate. Another innovation instituted in 1968 was the power granted to standing committees to submit reports on motions $\frac{0}{\mathbb{Q}}$ within their section of the agenda. At Aberdeen the Agenda $\stackrel{Q}{a}$ Committee was empowered to allocate block times for each $\overrightarrow{\overrightarrow{0}}$ main section of the agenda. It also had authority to select $\frac{3}{\sqrt{3}}$ motions or amendments for priority in debate. In this it was joined by the Meeting itself, which also had certain powers of selection-powers which it will undoubtedly use more when it becomes accustomed to them.

The excellent debates this year (see Supplement, 12 July, p. 9 ; and this week at p. 69) on abortion, I.M.S. Ltd., hospital junior doctors, and certification-to mention a few subjects-were without doubt owed in part to the new consti-을 tution of the Representative Body. Though it is still large and geographically representative its composition now reflects more closely the occupational groupings of the profession. This was particularly noticeable in the increased number of representatives from hospital practice, of whom there were N about 170. Not only did this allow for more thorough and ${ }_{\sigma}^{\omega}$ informed consideration of hospital matters, but different outlooks formed a refreshing feature of the debates. With no overwhelming preponderance of one section of the profession $\stackrel{\oplus}{+}$ over another matters of common interest tended to be dis- $\square$ cussed objectively and with a better understanding of the $\vec{P}$ problems of others. The value of this at a time when the N.H.S. is about to be reshaped needs no emphasis.

But, however good the procedural and constitutional arrangements, no meeting will be successful unless it is well led ando keeps to the matter in hand. The Chairman of the R.B. Dr. A. N. Mathias, at the end of his last year in office, contrito buted greatly to the success of the Aberdeen Meeting. And? the R.B. itself displayed much good sense and restraint. 